13

\title{
Влияние поэтапного постимплантационного отжига на состав и структуру поверхностных слоев кремния, имплантированного ионами щелочных металлов
}

\author{
(C) Б.Е. Умирзаков ${ }^{1}$, З.А. Исаханов ${ }^{2}$, Г.Х. Аллаёрова ${ }^{1}$, Р.М. Ёркулов ${ }^{2}$ \\ ${ }^{1}$ Ташкентский государственный технический университет, Ташкент, Узбекистан \\ ${ }^{2}$ Институт ионно-плазменных и лазерных технологий АН Узбекистана, Ташкент, Узбекистан \\ E-mail: be.umirzakov@gmail.com
}

Поступило в Редакцию 3 августа 2020 г.

В окончательной редакции 17 сентября 2020 г.

Принято к публикации 17 сентября 2020 г.

Изучена динамика изменения кристаллической структуры, элементного и химического состава поверхностных слоев $\mathrm{Si}$, имплантированного ионами $\mathrm{Na}^{+}, \mathrm{Rb}^{+}$и $\mathrm{Cs}^{+}$, при поэтапном отжиге при различных температурных режимах. Показано, что в случае ионов $\mathrm{Na}^{+}$после прогрева при температуре $T=900 \mathrm{~K}$ на поверхности образуется пленка $\mathrm{NaSi}_{2}$, при $T=1000 \mathrm{~K}$ - монослойное покрытие $\mathrm{NaSi}_{2}$, а при $T=1100 \mathrm{~K}$ поверхность и приповерхностные слои $\mathrm{Si}$ полностью очищаются от атомов легирующего элемента, кислорода и углерода.

Ключевые слова: ионная имплантация, силицид металла, эпитаксиальные слои, нанопленки, отжиг, дифракция быстрых электронов, монослойные покрытия, доза ионов.

DOI: 10.21883/PJTF.2021.01.50451.18494

При создании наноразмерных двух- и многослойных гетероструктур, обеспечивающих необходимые комбинации материалов для получения базовых элементов современной нано-, микро- и оптоэлектроники, широко используются методы молекулярной и твердофазной эпитаксии [1-6], а также метод низкоэнергетической $\left(E_{0} \leq 5 \mathrm{keV}\right)$ ионной имплантации в сочетании с отжигом [7-12]. Среди этих методов только метод ионной имплантации позволяет получать однородные сплошные пленки с толщиной $h \leq 40-50 \AA$. Для получения таких структур основными требованиями являются подготовка атомно-чистой поверхности подложки и обеспечение высокой чистоты напыляемых (имплантируемых) веществ. Все эти процессы выполняются в условиях сверхвысокого вакуума $\left(P \leq 10^{-8} \mathrm{~Pa}\right)$. При очистке монокристаллов $\mathrm{Si}$ очень важно найти надежный способ минимизировать присутствие на поверхности атомов кислорода и углерода. В работе [13] определены оптимальные режимы ионно-плазменной и химико-термической очистки поверхности кремния, которые позволяют уменьшить концентрации С и О до нуля (в пределах чувствительности оже-спектрометра $\sim 0.1$ at.\%).

Низкоэнергетические ионы, имплантируемые на небольшие глубины, на ранней стадии эпитаксиального роста пленки создают поверхностные дефекты, действующие в дальнейшем как центры кристаллического зародышеобразования. Энергия ионов стимулирует протекание химических реакций на поверхности, в частности образование тонких переходных слоев [14-18]. В определенных условиях ионная бомбардировка способствует ионно-стимулированной десорбции атомов $\mathrm{C}, \mathrm{O}$ и других загрязнений с поверхности. Однако до сих пор нет досто- верных данных по изучению динамики изменения морфологии, состава и структуры ионно-имплантированного Si при поэтапном отжиге в широком интервале температур.

Настоящая работа посвящена изучению изменения состава и структуры поверхностных слоев $\mathrm{Si}(111)$, имплантированного ионами щелочных металлов, в процессе отжига при различных температурных режимах.

В качестве объектов исследования были выбраны монокристаллические образцы $\mathrm{Si}(111)$ n-типа диаметром $10 \mathrm{~mm}$ и толщиной $0.5 \mathrm{~mm}$. Имплантация ионов, прогрев и все исследования проводились на одной и той же экспериментальной установке при вакууме не хуже $\left(P=10^{-7} \mathrm{~Pa}\right)$. Энергия ионов варьировалась в пределах от 1 до $5 \mathrm{keV}$, а их доза $D \approx 10^{14}-10^{17} \mathrm{~cm}^{-2}$. Источниками ионов служили стандартные хлоридные соли соответствующих щелочных элементов с чистотой $\sim 99.99 \%$. Перед ионной имплантацией источники ионов очищались длительным нагревом. После очистки источника в процессе образования паров щелочного элемента концентрация O на поверхности $\mathrm{Si}$ не изменялась. Для исследования состава и структуры был использован комплекс методов: электронная ожеспектроскопия (ЭОС), дифракция быстрых и медленных электронов (ДБЭ и ДМЭ соответственно) и вторичная ионная масс-спектрометрия (ВИМС). Растровые электронно-микроскопические (РЭМ) изображения были получены на стандартной установке ISM-6490 с разрешением 5-6 nm, а ДБЭ-картины - на установке ЭМР-2. Образование химической связи между атомами матрицы и имплантированного элемента оценивалось по изменению формы и положения оже-пиков типа $X V V$, 
Таблица 1. Зависимость параметра $а$ для разных типов ионов от их энергии $E_{0}$

\begin{tabular}{r|l|l|l|l|l}
\hline \multirow{2}{*}{$E_{0}, \mathrm{eV}$} & \multicolumn{5}{|c}{$a \cdot 10^{17}, \mathrm{~cm}^{2}$} \\
\cline { 2 - 6 } & $\mathrm{Li}^{+}$ & $\mathrm{Na}^{+}$ & $\mathrm{K}^{+}$ & $\mathrm{Rb}^{+}$ & $\mathrm{Cs}^{+}$ \\
\hline 500 & 6.0 & 6.8 & 21.3 & 36.5 & 49.0 \\
600 & 5.5 & 6.54 & 20.1 & 38.8 & 50.2 \\
700 & 5.6 & 6.8 & 20.2 & 43.2 & 53.1 \\
800 & 6.8 & 8.18 & 26.2 & 44.2 & 54.5 \\
900 & 8.9 & 9.8 & 30.1 & 43.8 & 57.6 \\
1000 & 9.0 & 10.36 & 34.1 & 52.6 & 62.5 \\
1100 & 7.08 & 9.27 & 35.6 & 53.5 & 62.0 \\
1600 & 6.95 & 9.37 & 33.1 & - & 61.5
\end{tabular}

Пр имечание. Прочерк - измерение не проводилось.

а концентрации атомов $\mathrm{Si}$, примесей и легирующих элементов - по изменению интенсивности высокоэнергетических пиков. Профили распределения атомов по глубине определялись методом ЭОС в сочетании с послойным травлением ионами аргона. Для сравнения были исследованы структура поверхности $\mathrm{Si}$ с монослойным покрытием $\mathrm{MeSi}_{2}$, полученная при напылении $\mathrm{Me}$ на $\mathrm{Si}$ с последующим отжигом. При образовании монослойного покрытия $\mathrm{MeSi}_{2}$ работа выхода еф поверхности Si уменьшается до минимума. Работа выхода из поверхности контролировалась методом контактной разности потенциалов. Методика эксперимента подробно описана в [15].

В процессе ионной имплантации происходит разупорядочение приповерхностного слоя и внедрение атомов легирующего элемента. Степень разупорядочения поверхности с большой точностью можно определить по картинам ДМЭ. Изменение дифракционной интенсивности будет определяться суммой двух эффектов: нарушения порядка атомного расположения и изменения состава поверхности. Для учета суммарного эффекта удобно контролировать изменение дефектности поверхности как функции отношения интенсивностей дифракционного рефлекса и упругого фона [15]. Измеряемыми величинами являются ток рефлекса и ток фона, которые пропорциональны соответственно первой степени площади, занятой порядком, и площади, занятой беспорядком. Поэтому зависимость изменения отношения токов рефлекса $\left(I_{r}\right)$ и фона $\left(I_{b}\right)$ от дозы облучения, согласно [15], имеет вид

$$
I_{r} / I_{b}=\left(I_{r 0} / I_{b 0}\right) \exp (-a D),
$$

где $I_{r 0} / I_{b 0}$ - значение отношения токов рефлекса и фона до облучения; $a$ - средняя площадь нарушения, приходящаяся на один ион; $D$ - доза облучения. В табл. 1 приведены экспериментальные значения $a$ для разных типов ионов в зависимости от их энергии $E_{0}$. Видно, что значение $a$ в зависимости от энергии ионов меняется немонотонно (с максимумом при $\sim 1000 \mathrm{eV}$ и минимумом при $650-700 \mathrm{eV})$. C ростом массы ионов

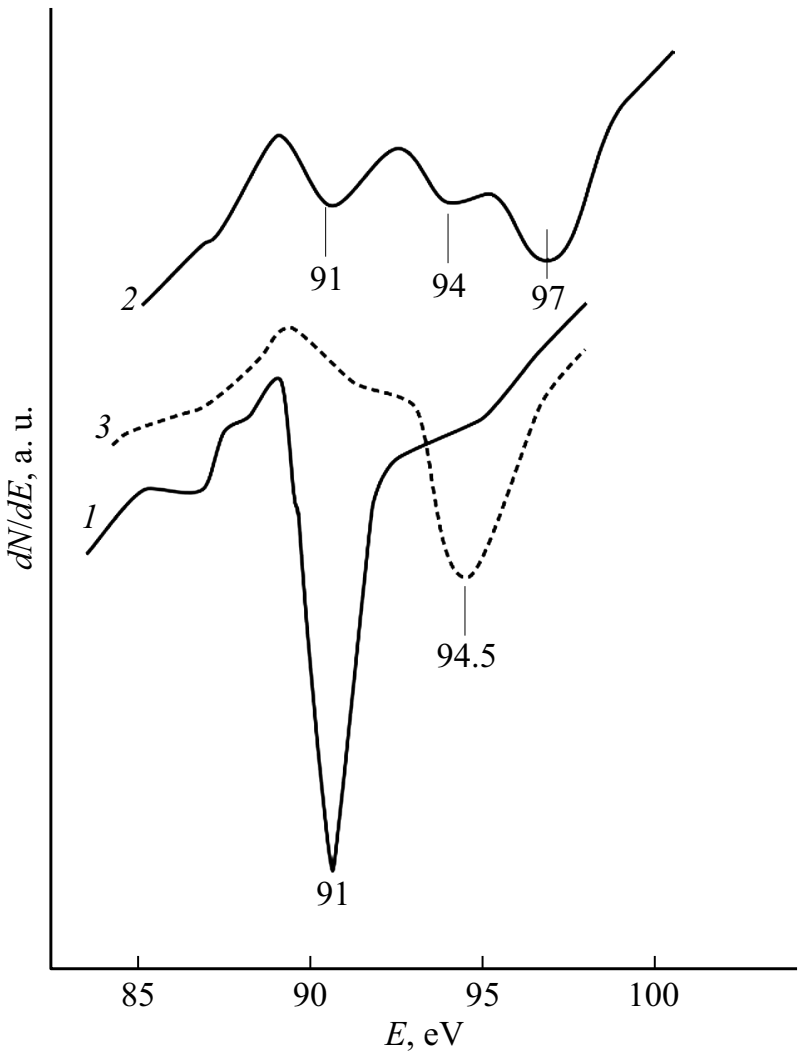

Рис. 1. Влияние имплантации ионов $\mathrm{Na}^{+}$и последующего отжига на интенсивность и положение $L_{23} V V$ оже-пика $\mathrm{Si} .1$ чистый $\mathrm{Si}(111), 2-\mathrm{Si}$, имплантированный ионами $\mathrm{Na}^{+}$с $E_{0}=1 \mathrm{keV}$ при $D=8 \cdot 10^{16} \mathrm{~cm}^{-2}, 3$ - после прогрева ионноимплантированного кремния при $T=900 \mathrm{~K}$ в течение $30 \mathrm{~min}$. Оже-спектры получены при энергии первичных электронов $E_{p}=2500 \mathrm{eV}$.

значение $a$ увеличивается. Одновременно можно было сравнивать значения $a$, измеренные по деградации только дифракционной интенсивности, которые были более чем на 1.5 порядка выше.

На рис. 1 приведены оже-спектры в интервале энергий $E=85-100 \mathrm{eV}$ (оже-линия $L_{23} V V$ кремния) для чистого $\mathrm{Si}$ и $\mathrm{Si}$, имплантированного ионами $\mathrm{Na}^{+}$с $E_{0}=1 \mathrm{keV}$ при $D=6 \cdot 10^{16} \mathrm{~cm}^{-2}$, до и после отжига при $T \approx 900 \mathrm{~K}$ в течение $30 \mathrm{~min}$. Видно, что после ионной имплантации интенсивность пика $\mathrm{Si}$ резко уменьшается и появляются новые пики, характерные для $\mathrm{NaSi}(E=96-97 \mathrm{eV})$ и $\mathrm{NaSi}_{2}(E=94-95 \mathrm{eV})$. После прогрева при $T \approx 900 \mathrm{~K}$ пики, соответствующие $\mathrm{NaSi}$ и $\mathrm{Si}$, исчезают, а пик $\mathrm{NaSi}_{2}$ увеличивается до максимума.

На рис. 2 приведены зависимости интенсивности оже-пиков $\mathrm{O}(506 \mathrm{eV})$ и $\mathrm{Na}(992 \mathrm{eV})$ от глубины $d$ для хорошо очищенного $\mathrm{Si}(111)$, а также после имплантации ионами $\mathrm{Na}^{+}$с энергией $E_{0}=1 \mathrm{keV}$ при $D=D_{\text {sat }}=8 \cdot 10^{16} \mathrm{~cm}^{-2}$, где $D_{\text {sat }}$ - доза насыщения. Проведенные на основе анализа оже-спектров расчеты показали, что концентрация О на поверхности чистого $\mathrm{Si}$ составляет 1.5at.\%. С ростом $d$ концентрация $\mathrm{O}$ 
Таблица 2. Температура формирования нанопленок силицидов $\mathrm{MeSi}_{2}$, температура образования монослоя $M е \mathrm{Si}_{2}$ и температура полной очистки поверхности $\mathrm{Si}$

\begin{tabular}{|c|c|c|c|c|c|c|c|}
\hline \multirow{2}{*}{ Ион } & \multirow{2}{*}{$E_{0}, \mathrm{keV}$} & \multirow{2}{*}{$D, \mathrm{~cm}^{-2}$} & \multicolumn{2}{|c|}{ Нанопленка $\mathrm{MeSi}_{2}$} & \multicolumn{2}{|c|}{ Монослой $\mathrm{MeSi}_{2}$} & \multirow{2}{*}{$T_{c r}, \mathrm{~K}$} \\
\hline & & & $T_{E}, \mathrm{~K}$ & $h, \AA$ & $T_{M}, \mathrm{~K}$ & $e \varphi, \mathrm{eV}$ & \\
\hline $\mathrm{Na}^{+}$ & $\begin{array}{l}0.5 \\
1.0\end{array}$ & $\begin{array}{l}6 \cdot 10^{16} \\
8 \cdot 10^{16}\end{array}$ & $\begin{array}{l}900 \\
950\end{array}$ & $\begin{array}{l}30-35 \\
35-40\end{array}$ & $\begin{array}{l}1000 \\
1000\end{array}$ & $\begin{array}{l}2.1 \\
2.1\end{array}$ & $\begin{array}{l}1100 \\
1100\end{array}$ \\
\hline $\mathrm{Rb}^{+}$ & 0.5 & $4 \cdot 10^{16}$ & 850 & - & $\begin{array}{r}950 \\
\end{array}$ & 1.95 & 1050 \\
\hline $\mathrm{Cs}^{+}$ & $\begin{array}{l}1.0 \\
0.5 \\
1.0\end{array}$ & $\begin{array}{l}6 \cdot 10^{16} \\
3 \cdot 10^{16} \\
5 \cdot 10^{16}\end{array}$ & $\begin{array}{l}900 \\
700 \\
700\end{array}$ & $\begin{array}{c}25-30 \\
- \\
20-25\end{array}$ & $\begin{array}{r}1000 \\
800 \\
-\end{array}$ & $\begin{array}{c}2.0 \\
1.8 \\
-\end{array}$ & $\begin{array}{r}1100 \\
900 \\
900\end{array}$ \\
\hline
\end{tabular}

Примеч ан ие. Прочерк — измерение не проводилось.

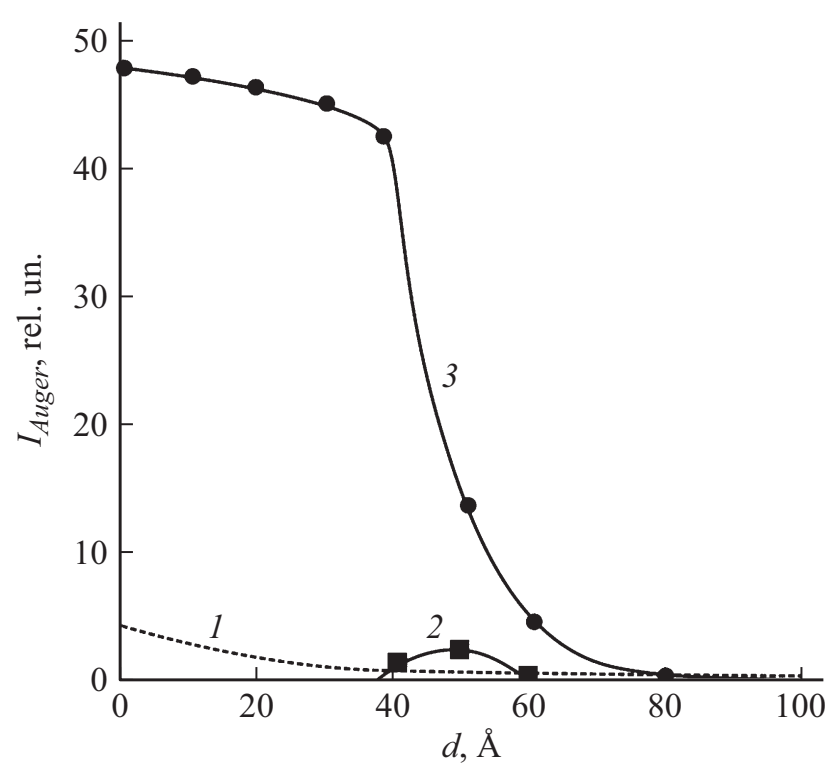

Рис. 2. Оже-профили распределения атомов по глубине: 1 кислорода в чистом $\mathrm{Si}(111), 2$ - кислорода в $\mathrm{Si}(111)$, имплантированном ионами $\mathrm{Na}^{+}$с $E_{0}=1 \mathrm{keV}$ при $D=6 \cdot 10^{16} \mathrm{~cm}^{-2}$, 3 - натрия в ионно-легированном кремнии.

монотонно уменьшается и начиная с $d=80-100 \AA$ практически не меняется, устанавливаясь на уровне $\sim 0.5$ at.\% (кривая 1 на рис. 2). В случае ионноимплантированного $\mathrm{Si}$ в сильнолегированной области $(d \simeq 0-35 \AA)$ атомы кислорода практически не обнаруживаются, но они накапливаются в области резкого спада натрия (кривые 2 и 3 на рис. 2). По-видимому, при ионной бомбардировке часть атомов кислорода испаряется с поверхности, а другая часть диффундирует в глубь образца до границы раздела ионно-легированный слой-кремний (кривая 2 на рис. 2). После отжига при $T \approx 900 \mathrm{~K}$ поверхностная концентрация 구 составляет $\sim 30-35$ at.\%, $\mathrm{Si} \sim 65-70$ at.\% и все атомы Na образуют химическую связь с атомами $\mathrm{Si}$. Концентрация этих атомов практически не меняется до глубины 30-35 at.\%. И в этих слоях формируется пленка $\mathrm{NaSi}_{2}$ с хорошей стехиометрией. При этом не происходит заметного изменения профиля распределения атомов О. Отжиг этой системы при $T \approx 1000 \mathrm{~K}$ приводит к уменьшению толщины пленки $\mathrm{NaSi}_{2}$ до одного монослоя, а отжиг при $T=1100 \mathrm{~K}-$ к полному испарению с поверхностных слоев атомов $\mathrm{Na}$ и его соединения с кремнием и кислородом (в пределах чувствительности оже-спектрометра). Результаты ВИМС показали, что при этом на поверхности и в приповерхностной области до глубины 60-80 А̊ имеется очень малое количество О, концентрация которого не превышает 0.1 at.\%, а оценочные значения концентрации углерода составляют $\sim 0.02$ at.\%. При $d \geq 100-150 \AA$, как в случае неимплантированного $\mathrm{Si}$, концентрация кислорода практически не меняется и устанавливается на уровне $\sim 0.3-0.5$ at.\%. В табл. 2 приведены температура образования $T_{E}$ эпитаксиальных слоев $\mathrm{MeSi}_{2}$, толщина $h$ этих слоев, температура образования монослоя $T_{M}$ силицида с соответствующей $е \varphi_{\min }$ и температура полной очистки $T_{c r}$ для $\mathrm{Si}$, имплантированного ионами $\mathrm{Na}^{+}, \mathrm{Rb}^{+}$и $\mathrm{Cs}^{+}$с энергиями 0.5 и $1.0 \mathrm{keV}$ при $D=D_{\text {sat }}$. Видно, что толщина пленок $\mathrm{MeSi}_{2}$, сформированных при одинаковых энергиях, в случае $\mathrm{Na}^{+}$ значительно больше, чем в случаях $\mathrm{Rb}^{+}$и $\mathrm{Cs}^{+}$. Это объясняется тем, что при $E_{0}=$ const с уменьшением диаметра атомов щелочного элемента глубина их проникновения и доза насыщения увеличиваются, а температура образования силицидной пленки уменьшается. Критическая температура очистки $T_{c r}$ поверхности и толщины очищенных слоев зависели от типа и энергии ионов. Для всех силицидов щелочных металлов температура полной очистки равна $1100 \mathrm{~K}$. Такую высокую степень очистки невозможно было получить при отжиге неимплантированного $\mathrm{Si}$ до $T \approx 1400-1500 \mathrm{~K}$ даже в сочетании с ионным травлением. Высокая чистота поверхности $\mathrm{Si}$ при выдержке в вакууме $P=10^{-7} \mathrm{~Pa}$ сохраняется в течение $10-15 \mathrm{~min}$, а в вакууме $P=10^{-9} \mathrm{~Pa}-$ в течение $1.5-2 \mathrm{~h}$.

На рис. 3, а приведены РЭМ-изображения и ДБЭкартина (верхняя вставка) для пленки $\mathrm{RbSi}_{2}$, полученные после прогрева при $T=900 \mathrm{~K}$ кремния, имплантированного ионами $\mathrm{Rb}^{+}$с $E_{0}=1 \mathrm{keV}$ при дозе $D=6 \cdot 10^{16} \mathrm{~cm}^{-2}$. Там же приведена ДМЭ-картина (нижняя вставка), полученная после прогрева этой систе- 
$a$
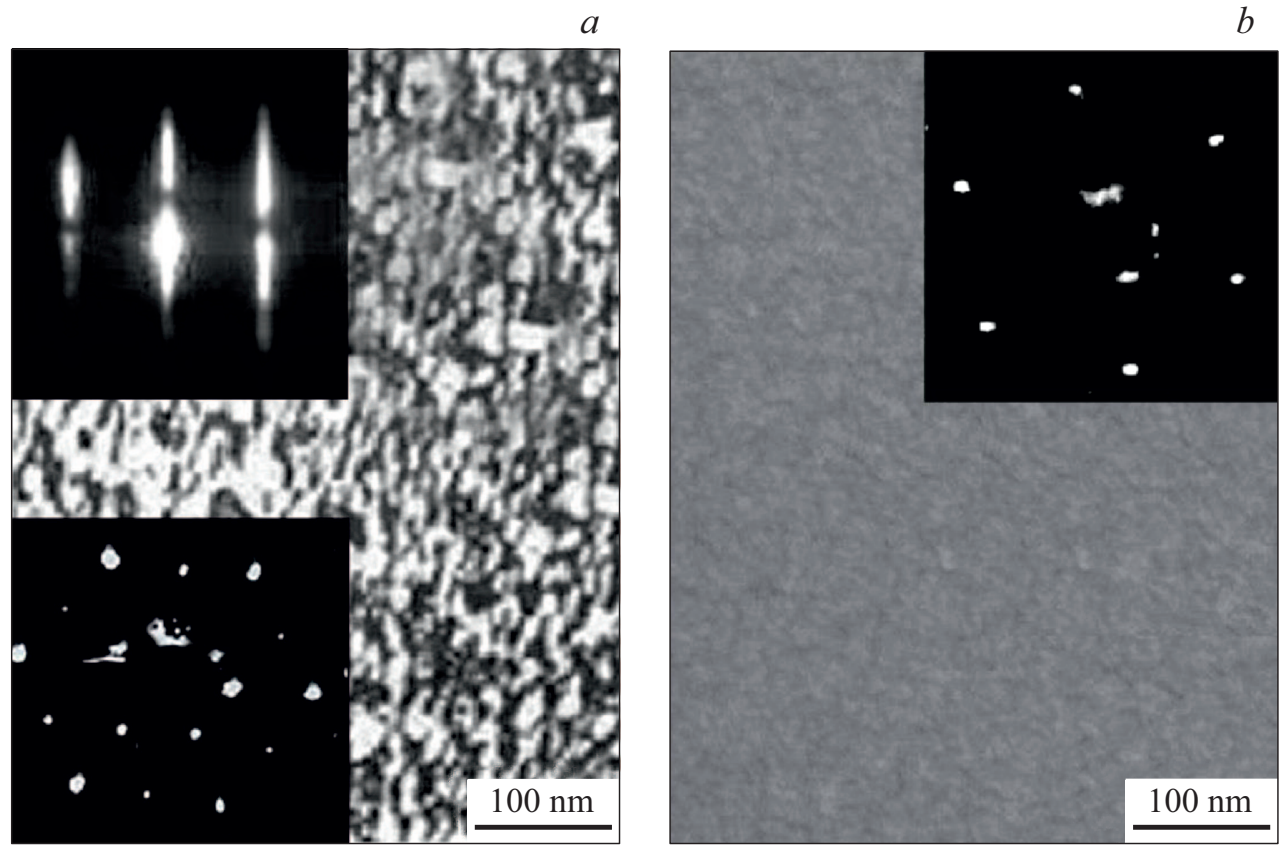

Рис. 3. $a$ - РЭМ-изображение поверхности пленки $\mathrm{RbSi}_{2} / \mathrm{Si}(111)$ толщиной 35-40 А. На верхней вставке - ДБЭ-картина пленки $\mathrm{RbSi}_{2}$, полученная при энергии электронного пучка $15 \mathrm{keV}$, на нижней - ДМЭ-картина $\mathrm{Si}(111)$ с монослойным покрытием $\mathrm{RbSi}_{2}$ : рефлексы с большими диаметрами относятся к $\mathrm{Rb}$, рефлексы с маленькими диаметрами - к дефектам несоответствия. $b-$ РЭМ-изображения и ДМЭ-картина (на вставке) поверхности системы $\mathrm{RbSi}_{2} / \mathrm{Si}(111)$, полученная после прогрева при $T=1100 \mathrm{~K}$. ДМЭ-картины получены при $E_{p}=54 \mathrm{eV}$.

мы при $T=1000 \mathrm{~K}$. Из рис. 3, $a$ видно, что поверхность пленки $\mathrm{RbSi}_{2}$ является относительно гладкой и пленка росла эпитаксиально (верхняя вставка), а поверхность $\mathrm{Si}$ с монослойным покрытием $\mathrm{RbSi}_{2}$ имеет структуру $2 \times 2$ (нижняя вставка). Последнее полностью совпадает со структурой $2 \times 2 \mathrm{RbSi}_{2}$, полученной нами ранее [15] при низкотемпературном осаждении слоев из ионных пучков с низкой энергией $\left(E_{0} \approx 500 \mathrm{eV}\right)$ и дозой $\left(D \approx 10^{5} \mathrm{~cm}^{-2}\right)$. Дальнейшие наши исследования показали, что все силициды щелочных металлов типа $\mathrm{MeSi}_{2}$ растут эпитаксиально, тем не менее их поверхность имеет различные структуры. Например, поверхность монослойного покрытия $\mathrm{LiSi}_{2}$ имеет структуру $3 \times 3$, а $\mathrm{NiSi}_{2}-1 \times 1$.

После прогрева при $T=1100 \mathrm{~K}$ независимо от типа силицидной пленки наблюдается ее полное испарение, а также испарение атомов кислорода и углерода. Поверхность $\mathrm{Si}$ становится однородной и гладкой (рис. $3, b$ ) и восстанавливается структура $1 \times 1$, характерная для чистого кремния (рис. $3, b$, вставка).

Таким образом, в работе впервые исследована динамика изменения состава и структуры поверхностных слоев ионно-имплантированного кремния при отжиге в различных температурных режимах. Показано, что в зависимости от температуры происходят следующие изменения: полная кристаллизация ионно-легированных слоев $\mathrm{Si}$ и образование силицидов типа $\mathrm{MeSi}_{2}$, формирование монослойного покрытия $\mathrm{MeSi}_{2}$, максимальная очистка поверхности и приповерхностных слоев Si.

\section{Конфликт интересов}

Авторы заявляют, что у них нет конфликта интересов.

\section{Список литературы}

[1] Л. Ченг, К. Плог, Молекулярно-лучевая эпитаксия и гетероструктуры, под ред. Ж.И. Алфёрова, Ю.В. Шмарцева (Мир, М., 1989).

[2] В.В. Золотарев, А.Ю. Лешко, А.В. Лютецкий, Д.Н. Николаев, Н.А. Пихтин, А.А. Подоскин, С.О. Слипченко, 3.Н. Соколова, В.В. Шамахов, И.Н. Арсентьев, Л.С. Вавилова, К.В. Бахвалов, И.С. Тарасов, ФТП, 47 (1), 124 (2013). http://journals.ioffe.ru/articles/4885

[3] М.А. Путято, Н.А. Валишева, М.О. Петрушков, В.В. Преображенский, Б.Р. Семягин, Е.А. Емельянов, А.В. Васев, А.Ф. Скочков, Г.И. Юрко, И.И. Нестеренко, ЖТФ, 89 (7), 1071 (2019). DOI: 10.21883/JTF.2019.07.47802.438-18 [Пер. версия: 10.1134/S106378421907020X].

[4] M.A. Green, K. Emery, Y. Hishikawa, W. Warta, E.D. Dunlop, D.H. Levi, A.W.Y. Ho-Baillie, Prog. Photovolt:: Res. Appl., 25 (1), 3 (2017). https://doi.org/10.1002/pip.2855

[5] P.R.C. Kent, A. Zunger, Phys. Rev. B, 64 (11), 115208 (2001). https://doi.org/10.1103/PhysRevB.64.115208

[6] В.И. Рудаков, Ю.И. Денисенко, В.В. Наумов, С.Г. Симакин, Письма в ЖТФ, 37 (3), 36 (2011).

http://journals.ioffe.ru/articles/12465

[7] S.B. Donaev, F. Djurabekova, D.A. Tashmukhamedova, B.E. Umirzakov, Phys. Status Solidi C, 12 (1-2), 89 (2015). https://doi.org/10.1002/pssc.201400156 
[8] B.E. Umirzakov, T.S. Pugacheva, A.T. Tashatov, D.A. Tashmukhamedova, Nucl. Instrum. Meth. Phys. Res. B, 166-167, 572 (2000). https://doi.org/10.1016/S0168-583X(99)01151-9

[9] 3.А. Исаханов, 3.Э. Мухтаров, Б.Е. Умирзаков, М.К. Рузибаева, ЖТФ, 81 (4), 117 (2011). [Пер версия: https://doi.org/10.1134/S1063784211040177].

[10] Y.S. Ergashov, B.E. Umirzakov, G.Kh. Allayarova, Mater. Sci. Appl., 9 (12), 965 (2018). https://doi.org/10.4236/msa.2018.912069

[11] Х.Х. Болтаев, Д.А. Ташмухамедова, Б.Е. Умирзаков, Поверхность. Рентгеновские, синхротронные и нейтронные исследования, № 4, 24 (2014). [Пер. версия: https://doi.org/10.1134/S1027451014010108].

[12] С.Б. Донаев, Письма в ЖТФ, 46 (16), 16 (2020). DOI: 10.21883/PJTF.2020.16.49847.18293 [Пер. версия: 10.1134/S1063785020080192].

[13] А.Г. Озеров, А.А. Алтухов, В.В. Иванов, Е.А. Титова, Техника средства связи, сер. ТПО, № 1, 111 (1987).

[14] L. Pelaz, L.A. Marques, J. Barbolla, J. Appl. Phys., 96 (11), 5947 (2004). https://doi.org/10.1063/1.1808484

[15] Б.Е. Умирзаков, С.Ж. Ниматов, Д.С. Руми, Структура и свойства многослойных нанопленочных систем, созданных на основе кремния (Infinity Group, Ташкент, 2013).

[16] J. Matsuo, T. Aoki, T. Seki, in 2007 Int. Workshop on junction technology (Kyoto, 2007), p. 53-54.

DOI: 10.1109/iwjt.2007.4279945

[17] С.Ж. Ниматов, Б.Е. Умирзаков, Ф.Я. Худайкулов, Д.С. Руми, ЖТФ, 89 (10), 1611 (2019). DOI: 10.21883/JTF.2019.10.48181.414-18 [Пер. версия: 10.1134/S1063784219100153].

[18] Б.Е. Умирзаков, Д.А. Ташмухамедова, Г.Х. Аллаярова, Ж.Ш. Содикжанов, Письма в ЖТФ, 45 (7), 49 (2019). DOI: 10.21883/PJTF.2019.07.47539.17650 [Пер. версия: $10.1134 / \mathrm{S} 1063785019040175]$. 